\title{
RESTROSPECTIVAS SOBRE O INSTITUTO DA ARBITRAGEM
}

Rachel Lopes Queiroz Chacur

Universidade do Oeste Paulista - UNOESTE. Curso de Direito, Presidente Prudente - SP. E-mail: $\underline{\text { rachel@unoeste.br }}$

\section{RESUMO}

Os objetivos das reformas do Código de Processo Civil estão pautados nas finalidades da Constituição Federal e na revisitação dos institutos processuais. O advento da Lei n.o 9307/1996 de 23 de Setembro de 1996 que regulamenta o instituto da Arbitragem, traz à tona o debate da eficácia da Lei e sua aplicabilidade como um dos meios alternativos de resolução de conflitos, com o fito de cumprir os objetivos do processo e alcançar a pacificação social.

Palavras-chave: Arbitragem, Meio Alternativo e Processo Civil.

\section{RESTROSPECTIVAS ABOUT THE INSTITUTE OF ARBITRATION}

\section{ABSTRACT}

The objectives of the Code of Civil Procedure reforms are guided in the purposes of the Federal Constitution and the revisiting of procedural institutes. The enactment of Law No. 9307/1996 of September 23, 1996 which regulates the Institute of Arbitration, brings up the debate of the effectiveness of the Act and its applicability as a means of alternative dispute resolution, with the aim of fulfilling process objectives and achieve social peace.

Keywords: Arbitration, Civil Procedure and Alternative Means. 
INTRODUÇÃO

O breve relato da evolução histórica processual consta o instituto da Arbitragem na Constituição de 1824, regulada pelo Código Comercial de 1850 e Regulamento 737. O instituto era aplicado para as hipóteses de relações comerciais. A Lei n.ำ 1350 de 1866 extinguiu a arbitragem obrigatória para todos os casos. Com o advento da proclamação da República, cada Estado Membro criou legislação própria sobre a aplicabilidade da Arbitragem, para determinadas relações contratuais naquela região, dando caráter de voluntariedade para o instituto ${ }^{1}$. Nesse período, havia distinção conceitual de cláusula compromissória e compromisso. A cláusula compromissória estabelecia no contrato, a possibilidade da submissão do conteúdo contratual no Tribunal de Arbitragem e à posteriori a conversão desta em um compromisso arbitral. Na eventualidade de apreciação do objeto litigioso ou da execução do laudo arbitral, a legislação brasileira obrigava a homologação judiciária . O Poder Judiciário verificava a regularidade formal do laudo arbitral e a idoneidade do compromisso.

O Protocolo de Genebra ${ }^{2}$ ratificado pelo Brasil e promulgado o Dec. 21187, de 22-031932 equiparava a cláusula compromissória ao compromisso, pois interessava à arbitragem comercial internacional.

No entanto, o Dec. 21187, de 22-03-1932 e o Protocolo de Genebra, tratou-o como norma jurídica de fonte interna e internacional de direito. Alguns doutrinadores ${ }^{3}$ entendiam que norma específica prevalecia à norma genérica, assim como regra, admitiam a aplicação do Princípio da Especialidade.

O entendimento do Supremo Tribunal Federal (STF) pressupôs a igualdade de hierarquia dessas normas jurídicas, prevalecendo à norma mais recente.

No ano de 1975, a Convenção Interamericana sobre Arbitragem Comercial Internacional, ratificada pelo Brasil, admitia a equiparação da cláusula compromissória e ao compromisso arbitral. Entretanto, a jurisprudência pátria ${ }^{4}$ divergiu da equiparação da cláusula compromissória ao compromisso arbitral, decidindo que o Protocolo de Genebra fora revogado pelo Código de Processo Civil.

\footnotetext{
${ }^{1}$ Lei no 1416 , 14.07.1914 do Estado de São Paulo. Instituição do Instituto da Arbitragem para relações contratuais de compra e venda de café.

${ }^{2}$ O Protocolo, em seu artigo 1으, determina: "Cada um dos Estados contratantes reconhece a validade, entre partes submetidas respectivamente à jurisdição de Estados contratantes diferentes, do compromisso ou da cláusula compromissória pela qual as partes num contrato se obrigam, em matéria comercial ou em qualquer outra suscetível de ser resolvida por meio de arbitragem por compromisso, a submeter, no todo ou em parte, as divergências que possam resultar de tal contrato a uma arbitragem, ainda que esta arbitragem deva verificar-se num país diferente daquele a cuja jurisdição está sujeita a qualquer das partes no contrato."

${ }^{3}$ TIBURCIO, Carmem apud BAPTISTA, Luis Olavo. A arbitragem no Direito brasileiro: Histórico e Lei no 9307/1996. Editora Revista dos Tribunais, Revista de Processo, REPRO 104, ano 26, outubro-dezembro, p-83, 2001.

${ }^{4}$ Resp 616, j. 24-07-1990, publicado no DJ 13-08-1990, p- 7.647.
} 
No ano de 1979, a ratificação da Convenção Interamericana sobre a Eficácia Extraterritorial das Sentenças e Laudos Arbitrais Estrangeiros, a qual trata da homologação dos laudos arbitrais prolatados no exterior.

No Brasil, a arbitragem internacional necessitava de dupla homologação e a citação da parte domiciliada no Brasil, por carta rogatória, para os casos de arbitragem instalada no exterior.

As decisões de homologação de laudos arbitrais elaborados no exterior, pelo Supremo Tribunal Federal (STF) estabelecia a necessidade de comprovação das funções judicantes da autoridade arbitral e a prova da exequibilidade do laudo arbitral, no país estrangeiro ${ }^{5}$.

Segundo José Carlos Barbosa Moreira ${ }^{6}$ a sentença deve ser entendida pelo os efeitos de seu conteúdo, independente da denominação ou forma prevista no ordenamento jurídico estrangeiro.

É competente o Supremo Tribunal Federal para a homologação do laudo arbitral, porém se a decisão é homologada no país de origem, não há o porquê da homologação pelo país estrangeiro; conclui o doutrinador.

A promulgação da Lei n.o 9307, de 23 de Setembro de 1996 solucionou o conflito aparente de normas de direito público interno e internacional, revitalizando o instituto da arbitragem, no Brasil.

A finalidade primordial é incentivar a criação de meios alternativos para a solução dos conflitos, dentre eles o instituto da Arbitragem.

Segundo John Cooley ${ }^{7}$, o instituto da arbitragem é uma alternativa para dar resposta ao consumidor da Justiça, o cliente do Poder Judiciário.

Os advogados que levavam seus casos aos tribunais submetiam-se a uma controvérsia aparentemente infinda, de alta tortura... com a hipótese do pior cenário possível: submeter seus clientes à pobreza vitalícia. Felizmente, para os advogados, hoje em dia, há alternativas. Podemos aprender sobre métodos novos, inovadores, para resolver disputas, quando o processo judicial não parece proporcionar a melhor alternativa procedimental para satisfazer as necessidades e os interesses emocionais e psicológicos de nossos clientes, e aplicar esses métodos.

A tendência de transferência da titulariedade da função jurisdicional do Poder Judiciário para estruturas administrativas e para-legais.

\footnotetext{
${ }^{5}$ RTJ 109/501.

${ }^{6}$ BARBOSA MOREIRA, José Carlos. Comentários ao Código de Processo Civil. Editora Forense, 8a edição, vol. V, p- 63.b Portanto, qualquer decisão estrangeira que ponha termo ao processo em primeira instância deve ser equiparada a uma sentença, bem como qualquer decisão que ponha termo ao processo em grau superior também será homologável, desde que, obviamente, seja exeqüível no país onde proferida.

${ }^{7}$ COOLEY, John W., LUBET Steven. Advocacia de Arbitragem. Tradução de René Locan, Brasília, UNB, 2000, p-15.
} 
O Estado e o Poder Judiciário delegam essa função de solução dos conflitos para a sociedade, para as universidades, para as organizações não-governamentais, às instituições religiosas e educacionais.

Assegura Inocêncio Mártires Coelho ${ }^{8}$ a mobilização social na solução dos conflitos objetiva a redução da litigiosidade contida perante as funções estatais e jurisdicionais.

No sentido teleológico, a sua finalidade é a pacificação de pessoas e eliminação de conflitos com justiça.

A Lei da Arbitragem facilita o aperfeiçoamento das relações comerciais nacionais e internacionais e colabora com as normas internacionais delimitadoras do instituto, como o Protocolo de Genebra (1923), o Tratado de Genebra (1927), a Convenção Interamericana Panamá (1975), a Convenção Interamericana Montevidéu (1979), Lei Modelo Arbitragem Comercial da UNCITRAL, Convenção de Nova York (1958), Convenção BIRD (1965 e 1991), Protocolo de Brasília (1991) e Protocolo de Buenos Aires.

O compêndio de Paulo de Tarso Santos ${ }^{9}$ apresenta o instituto da Arbitragem, como um avanço científico para o Brasil.

A doutrina constitucional denomina a tendência da miniminização do Poder Estatal.

O conceito do instituto da arbitragem apresentado por Tânia Lobo Muniz" 10 "A arbitragem é meio eficaz e válido para a solução de litígios, internamente pela celeridade na prestação da justiça, principalmente diante da morosidade e da crise do Judiciário, e externamente pelas características das relações internacionais. "11

A obra Tânia Lobo Muniz ${ }^{12}$ elenca os seguintes fundamentos do instituto da arbitragem: a celeridade e a informalidade, a neutralidade, a confidencialidade, a especialização, a confiabilidade e a equidade.

São marcantes as características do tratamento igualitário, a isenção dos tribunais de arbitragem, o sigilo profissional, a escolha de árbitros pelos seus conhecimentos técnicos pelas partes e a ênfase aos fatos relatados pelas partes.

O instituto da arbitragem apresenta natureza híbrida ${ }^{13}$ : autonomia da vontade das partes para a opção do instituto, e natureza jurisdicional do órgão arbitral, da investidura e atuação do árbitro, procedimento e eficácia das sentenças arbitrais ${ }^{14}$.

\footnotetext{
${ }^{8}$ COELHO, Inocêncio Mártires. Constitucionalidade/Inconstitucionalidade: uma questão política? Revista Jurídica virtual. Brasília, n.13, junho de 2000.

${ }^{9}$ SANTOS, Paulo de Tarso. Arbitragem e Poder Judiciário (Mudança Cultural). Editora LTr, São Paulo, 2001.

${ }^{10}$ MUNIZ, Tânia Lobo. Arbitragem no Brasil e a Lei 9307/1996. Editora Aruá, 1999, p-15. é meio eficaz e válido para a solução de litígios, internamente pela celeridade na prestação da justiça, principalmente diante da morosidade e da crise do Judiciário, e externamente pelas características das relações internacionais.

${ }^{11}$ MUNIZ, Tânia Lobo. Arbitragem no Brasil e a Lei 9307/1996. Editora Aruá, 1999, p-15.

${ }^{12}$ MUNIZ, Tânia Lobo. Arbitragem no Brasil e a Lei 9307/1996. Editora Aruá, 1999.
} 
A legislação em vigor estabelece a equiparação do laudo arbitral à sentença judicial e a possibilidade de conversão da cláusula compromissória, em compromisso.

Para Paulo Cezar Pinheiro Carneiro ${ }^{15}$ a decisão arbitral produz coisa julgada material e somente poderá ser desconstituída pela decretação da nulidade da sentença.

A sentença arbitral é um título executivo extrajudicial e o seu descumprimento acarreta a propositura da ação executiva ${ }^{16}$.

A convenção de arbitragem, a qual engloba a cláusula compromissória e o compromisso arbitral, ambas são obrigatórias na instauração do juízo arbitral. A cláusula compromissória é submetida ao juízo arbitral e se uma das partes requerer a revogação da decisão arbitral, essa deverá constar a anuência da outra parte, para a respectiva demanda no Poder Judiciário, desta decisão judicial advém o compromisso arbitral.

Há controvérsias sobre a validade e eficácia da Arbitragem.

A inovação da Lei n. 9 9307/1996 extingue o sistema de dupla homologação e a admite de citação via postal para a parte domiciliada no Brasil, mas não elenca o procedimento e o funcionamento das Comissões de Arbitragem.

O entendimento de alguns operadores do direito é que a legislação pertinente é um retrocesso para os procedimentos extrajudiciais.

\section{CONCLUSÃO}

A celeuma acerca do tema da eficácia da Lei da Arbitragem culminou no debate da jurisprudência sobre a equiparação da cláusula compromissória e do compromisso arbitral, para as relações comerciais submetidas à arbitragem internacional.

A equiparação da sentença arbitral à sentença judicial, não solucionaram as divergências das regras de homologação do laudo arbitral e da sentença judicial, proferidos no país estrangeiro.

O Supremo Tribunal Federal (STF) previa as hipóteses de exclusão da competência para a homologação de sentenças estrangeiras.

O artigo 38 e 39 da Lei de Arbitragem estabelecem as regras específicas para a homologação do laudo arbitral, em contrapartida também trata a eficácia das sentenças proferidas no país de origem e estrangeiros.

A discussão doutrinária e jurisprudencial $^{17}$ enfoca a constitucionalidade ou inconstitucionalidade da Lei de Arbitragem. A inconstitucionalidade suscitada pelo Ministro José

\footnotetext{
${ }^{13}$ MUJALLI, Walter Brasil. Juízo Arbitral. A nova Lei de arbitragem. Comentários e legislação à Lei no 9037 de 23/09/1996. Editora de Direito, 1997.

${ }^{14}$ KROETZ, Tarcisio Araújo. Arbitragem Conceito e Pressupostos de validade. Editora Revista dos Tribunais, 1 ạ edição, 1997.

${ }^{15}$ CARNEIRO, Paulo Cezar Pinheiro. Aspectos processuais da nova Lei da Arbitragem. RF 339/127-141, esp. p-137.

${ }^{16}$ MAGALHÃES, José Carlos. Reconhecimento e execução de laudos arbitrais estrangeiros. RT 740/116-127, esp. p-116/117, 1997. 
Carlos Moreira Alves, reiterada por Sidney Sanches e pelo o relator Sepúlveda Pertence, embasada na necessidade de conversão forçada da cláusula compromissória, no compromisso arbitral. O artigo 7으 da Lei de Arbitragem foi declarado inconstitucional pelo $\mathrm{STF}^{18}$, com o entendimento que a cláusula compromissória estabelecia uma mera obrigação de fazer e o compromisso resultaria na instauração da arbitragem. Para o ministro Sepúlveda Pertence ${ }^{19}$, a renunciabilidade ao direito de ação, deve ser posterior a formação da lide, sendo que somente as partes podem renunciar a via estatal e optar pelo juízo arbitral. A recusa de uma das partes do conflito ser submetido ao procedimento arbitral ou a manifestação contrária a cláusula compromissória permitiria o juiz togado, substituir a vontade das partes, isto seria uma afronta ao princípio da inafastabilidade do Poder Judiciário ${ }^{20}$. O seu voto admite a validade do compromisso arbitral e a constitucionalidade do juízo arbitral somente se estabelecido por força de lei.

O Ministério Público Federal através do ofício do Procurador Geraldo Brindeiro externa a manifestação favorável ao entendimento parcial da constitucionalidade da Lei da Arbitragem.

O Agravo Regimental n.o 5206-7 ficou suspenso pelo prazo temporal de 3 (três) anos e reiniciou seu trâmite em novembro de 2000.

O ministro Nelson Jobim ${ }^{21}$ manifestou entendimento pela constitucionalidade da Lei de Arbitragem. Consigna o ínclito ministro que, a implantação das Comissões de Arbitragem não ofende o Acesso à Justiça, uma vez que a cláusula compromissória permite que o juiz substituto a vontade da parte reclacitrante em firmar o compromisso e enseja na demanda judicial.

O andamento do recurso supracitado permanece suspenso, em virtude do pedido de vistas do ministro Ilmar Galvão.

As manifestações pela constitucionalidade da Lei da Arbitragem sobrepesam até a decisão final do Agravo Regimental.

A doutrina pátria discute o aprimoramento da sistematização do instituto da Arbitragem, porém permanecem dúvidas à respeito da eficácia das decisões proferidas por este Juízo, inclusive nos países estrangeiros. A orientação doutrinária e jurisprudencial é para inserir nas cláusulas arbitrais dos contratos supranacionais, a obrigatoriedade do julgamento no exterior ou simplesmente a elaboração desses contratos, no Brasil.

\footnotetext{
${ }^{17}$ AgRg SE 5.206-7. O Agravo Regimental interposto pela empresa suíça, uma vez que a empresa brasileira pedia a homologação do laudo arbitral para efetuar o pagamento da condenação, mas por maioria de votos dos 11 ministros, o STF entendeu que havia a necessidade de homologação pelo Tribunal da Espanha.

${ }^{18}$ É o entendimento do Pleno do Supremo Tribunal Federal, no dia 13 de Dezembro de 2001.

${ }^{19}$ AgRg SE 5.206-7, p-31 e 35. No mesmo sentido: RTJ 117/57, SE 3.894-3, RTJ 95/1.011, 125/76, 127/94, 133/607 e AgRg SE 5.206-7, p-31 e 35.

${ }^{20}$ Artigo 5o, inciso XXXV da Constituição Federal.

${ }^{21}$ Idem, ibidem. 
Os dados estatísticos omitem os resultados reiterados das Comissões de Arbitragem, não se podendo auferir a colaboração desse meio alternativo de solução de conflitos para com a efetividade do processo e da tutela jurisdicional.

\section{REFERENCIAS}

BARBOSA MOREIRA, José Carlos. Comentários ao Código de Processo Civil. Editora Forense, 8a edição, vol. V, p- 63.b.

CARNEIRO, Paulo Cezar Pinheiro. Aspectos processuais da nova Lei da Arbitragem. RF 339/127141, esp. p-137.

COELHO, Inocêncio Mártires. Constitucionalidade/Inconstitucionalidade: uma questão política? Revista Jurídica virtual. Brasília, n.13, junho de 2000.

COOLEY, John W., LUBET Steven. Advocacia de Arbitragem. Tradução de René Locan, Brasília, UNB, 2000, p-15.

KROETZ, Tarcisio Araújo. Arbitragem Conceito e Pressupostos de validade. Editora Revista dos Tribunais, 1a edição, 1997.

MAGALHÃES, José Carlos. Reconhecimento e execução de laudos arbitrais estrangeiros. RT 740/116-127, esp. p-116/117, 1997.

MUJALLI, Walter Brasil. Juízo Arbitral. A nova Lei de arbitragem. Comentários e legislação à Lei no 9037 de 23/09/1996. Editora de Direito, 1997.

MUNIZ, Tânia Lobo. Arbitragem no Brasil e a Lei 9307/1996. Editora Aruá, 1999, p-15.

SANTOS, Paulo de Tarso. Arbitragem e Poder Judiciário (Mudança Cultural). Editora LTr, São Paulo, 2001.

TIBURCIO, Carmem apud BAPTISTA, Luis Olavo. A arbitragem no Direito brasileiro: Histórico e Lei no 9307/1996. Editora Revista dos Tribunais, Revista de Processo, REPRO 104, ano 26, outubrodezembro, p-83, 2001.

\section{JURISPRUDÊNCIAS:}

Resp 616, j. 24-07-1990, publicado no DJ 13-08-1990, p- 7.647. RTJ 109/501.

AgRg SE 5.206-7. O Agravo Regimental interposto pela empresa suíça, uma vez que a empresa brasileira pedia a homologação do laudo arbitral para efetuar o pagamento da condenação, mas por maioria de votos dos 11 ministros, o STF entendeu que havia a necessidade de homologação pelo Tribunal da Espanha.

AgRg SE 5.206-7, p-31 e 35. No mesmo sentido: RTJ 117/57, SE 3.894-3, RTJ 95/1.011, 125/76, 127/94, 133/607 e AgRg SE 5.206-7, p-31 e 35. 